\title{
A time to keep silent and a time to speak
}

\section{Reviewing the Mental Health Act}

\author{
A. S. Zigmond
}

The final report of the Scoping Study Committee (Richardson Committee) reviewing the Mental Health Act 1983 is eagerly awaited. All psychiatrists, either individually or through the College, had an opportunity to express their views on what changes in legislation are needed and to comment on the draft proposals (Scoping Study Committee, 1999). Many psychiatrists did neither. Yet to use modern terminology, psychiatrists are one of the major 'stakeholders' of mental health legislation. A valuable way of ascertaining colleagues' views in a structured way is by surveys of the type conducted by Buchanan \& Gunn (1999, this issue). Given that the Richardson Committee has yet to publish proposals for 'Part III' the survey is timely. The response rate is, of course, very important and one is left wondering why a third of the general and community psychiatrists did not respond. Work load, burn-out or lack of familiarity with Part III of the Act are possible explanations.

The value of a piece of legislation may, in part, be determined by its uptake. The use of Part III of the Act has increased over the years, but not in line with detentions under Part II. In the 10 years 1987-1997 the number of court and prison disposals increased by $27 \%$. This is due to a four-fold increase in transfers from prison to hospital (the prison population increased by $26 \%$ during this time suggesting some real attempt to address the needs of the mentally ill in prison (Office for National Statistics, 1999)).

The number of detentions under Sections 3538 has fallen by $11 \%$. In the same period the number of admissions under Part II of the Act increased by $70 \%$. There may be many explanations for this: the success of Court Diversion Schemes, the perceived lack of flexdbility of Part III of the Mental Health Act, the inability to treat patients compulsorily under Section 35, the reluctance to take to court patients who could be detained under civil sections and lack of familiarity with Part III. Equally it might be used as evidence to support the need for change.
The legal categories of mental disorder are the same for all parts of the Act. It may be said that the category 'psychopathic disorder' is the most controversial and is certainly little used. This may be due to the requirement that treatment will 'alleviate or prevent a deterioration' in the patient's condition. Under $1 \%$ of compulsory detentions are classified as psychopathic disorder (Mental Health Act Commission, 1999). There was considerable debate prior to the 1983 Act as to whether or not this category should exist. Psychiatrists appear to be voting with their detention papers.

Part III of the Act is used for a number of differing groups of patients. Provision for the assessment and treatment in hospital of the mentally ill (who, perhaps coincidentally, have committed a crime) is not controversial and is, in one way or another, mirrored in the civil sections. At least it is not controversial for psychiatrists. Many patients resent receiving what they view as an indeterminate sentence for what may have been a relatively trivial crime. The suggestion (Buchanan \& Gunn, 1999, this issue) that patients should be detainable in hospital under Part III of the Act in circumstances when they could not have been detained by imprisonment may cause considerable disquiet. The Home Office \& Department of Health (1999) proposals go further. Psychiatrists will surely have views on the renewable or indeterminate detention of people who neither want nor are amenable to treatment and who have committed no offence, on the grounds that they suffer from a severe personality disorder.

The law can neither provide a 'quick-fix' solution nor can it substitute for a properly resourced service. People with mental illnesses, including those who offend, deserve fairness. Neither the quality of services nor the legislative framework should be stigmatising. We are assured there will be a further consultation period following publication of the Richardson Committee's final report. Now is the time to speak. 


\section{References}

OFFiCE FOR NATIONAL STATISTICs (1999) Annual Abstract of Statistics. London: The Stationery Office.

Buchanan, A. \& GuNN, J. (1999) What do psychiatrists think about Part III of the Mental Health Act? Psychiatric Bulletin, 23, 721-725.

HOME OFFIC \& DEPARTMENT OF HEALTH (1999) Managing Dangerous People With Severe Personality Disorder. London: Home Office.
Mental Health Act Commission (1999) Eighth Biennial Report. Nottingham: Mental Health Act Commission. Scoping STUdY COMMrTte (1999) Draft Outline Proposals. London: Department of Health.

A. S. Zigmond, Consultant Psychiatrist, High Royds Hospital, Menston, West Yorkshire LS29 $6 A Q$

\section{Visit the Royal College of Psychiatrists website at http://www.rcpsych.ac.uk}

\section{Information on:}

- college books, reports, and journals $\downarrow$ press and public initiatives

$\downarrow$ conferences $\downarrow$ information services $\downarrow$ examinations

$\downarrow$ postgraduate education $\downarrow$ the college research unit

\section{And for members, information on:}

$\diamond$ divisions $\diamond$ faculties $\diamond$ sections $\diamond$ SIGS $\diamond$ committees and more

For further information please contact Lucy Alexander:

email: lalexander@rcpsych.ac.uk, tel: 01712352351 ext 120 